\title{
Tree Stand-Related Injuries in Nonadmitted and Admitted Patients at a Level 2 Trauma Center in Michigan: 2015-2019
}

\author{
Alan A. Lazzara Jr., MD, FAWM, FACEP; Bailey I. Ditmer, DO; Kyle W. Doughty, DO; Kyle R. Reynolds, DO \\ Henry Ford Allegiance Health Emergency Department, Jackson, Michigan
}

\begin{abstract}
Introduction-Tree stand-related injuries (TSRI) are more common than firearm-related injuries in hunters. Most previous studies on the topic used trauma databases that only include admitted patients. This study characterizes injury patterns found in nonadmitted and admitted TSRI patients presenting to a level 2 Michigan trauma center. TSRI prevention interventions are also discussed.

Methods - Cases were obtained through a retrospective chart review of the Henry Ford Allegiance Health trauma registry and EPSi cost-accounting database from 2015 to 2019. Keywords searched included fall, hunter, tree, tree stand, treestand, ICD 9 diagnosis (E884.9_Other accidental fall from one level to another), and ICD 10 diagnosis (W14.XXXA_Fall from tree, initial encounter). We analyzed age, sex, body mass index, injury severity score, disposition, alcohol use, injuries sustained, reported height of fall, and narrative of fall.

Results-Thirty-three patients were identified. Patient age was $45 \pm 13$ y (mean \pm SD). All patients were male. Injury severity score for nonadmitted patients was $2 \pm 1$ vs $13 \pm 11$ in admitted patients. Thirty-three percent of cases were nonadmitted; $67 \%$ were admitted. The most common injuries sustained were spinal $(33 \%)$ and lower extremity fractures $(15 \%)$. The average yearly TSRI case rate was 5.73 per 10,000 hunters in the study area.

Conclusions-Our study found that spinal and lower extremity fractures were the most common injuries sustained. One-third of our patients were nonadmitted and therefore not included in the Henry Ford Allegiance Health trauma registry. Some nonadmitted patients had significant injuries requiring specialist consultation, orthopedic braces, or outpatient surgery.
\end{abstract}

Keywords: fall, hunting, hunter, elevated platform, trauma

\section{Introduction}

Hunting remains a popular avocation for many Americans. According to the National Survey of Fishing, Hunting, \& Wildlife-Associated Recreation, it is estimated that between 5 and $8 \%$ of all Americans age $16 \mathrm{y}$ and older participate in hunting. ${ }^{1-3}$ Percentages vary by geographic region of the United States and year. ${ }^{1-3}$ Recent decades have shown a decline in annual hunting participation prevalence estimates. From 2006 to 2016, the number of hunters decreased from 12.5 million to

Corresponding author: Alan A. Lazzara Jr., MD, FAWM, FACEP, Henry Ford Allegiance Health Emergency, 407 Pineway Drive, Ann Arbor, MI 48103; e-mail: alan.a.lazzara@gmail.com.

Submitted for publication January 2021.

Accepted for publication August 2021.
11.5 million, with a drop in big game hunters from 10.7 million to 9.2 million. ${ }^{1-3}$ Deer hunters comprise the overwhelming majority of not only big game hunters, but also US hunters in general. ${ }^{1-3}$ These national surveys characterize the archetypal hunter as a middle-aged white male who began hunting in his youth. However, in the past 2 decades the pursuit has gained popularity among women and hunters who adopt the pastime as adults..$^{1-3}$

Tree stands are predominantly used to hunt big game animals, particularly deer. Tree stands confer an advantage to the hunter through scent dispersal, reduced visibility by game, and increased field of view. Stand use is prevalent in midwestern, eastern, and southeastern states owing to the type of habitat available for hunting (eg, agricultural fields, forest). There are 5 main tree 


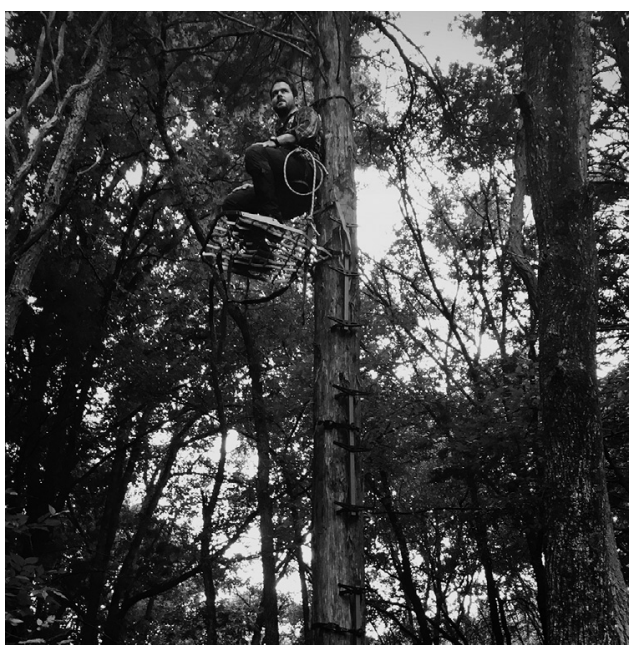

Figure 1. Bowhunter preparing a hang-on platform tree stand for deer season. Note the hunter's safety harness and attachment to tree near upper back. Photo courtesy Philip J. Lazzara.

stand categories: homemade wooden platforms, metal ladder stands, 2-piece metal climbers, hang-on platforms (Figure 1), and tree saddles. Hunters usually positions themselves 3 to $9 \mathrm{~m}$ (10-30 ft) from ground level, finding a balance between prey sight line and shot angle.

The prototypical patient with a tree stand-related injury (TSRI) is a 38 - to 45 -y-old white male. ${ }^{4}$ The most frequent serious injuries are lower extremity or spinal column fractures with or without spinal cord injury. ${ }^{5-13}$ The overwhelming majority of hunters who fall are not wearing a fall arrest system or safety harness. ${ }^{8-16}$ Some studies show that the fallen hunter is most commonly engaged in archery hunting and falls while descending or ascending a stand in the evening hours. ${ }^{16,17}$

Numerous efforts have been undertaken to make hunting from a tree stand safer, and most focus on hunter education. Since the early 2000s, US state game agencies have included tree stand safety information in the 2-d hunter's education/safety course. Completion of this course is required to purchase a base hunting license and applicable game tags. However, the course is taken only once, potentially leaving many years without formal reminders on gun, archery, or tree stand safety. In 2004, the nonprofit Tree Stand Manufacturer's Association advocated with the Consumer Product Safety Commission to support industry standard equipment specifications for manufactured stands and the inclusion of a fall arrest system in every tree stand sold. In 2007, written material and a DVD on tree stand safety were added as a requirement for manufacturers seeking Tree Stand Manufacturer's Association safety certification. ${ }^{6}$ Two states, Alabama and Mississippi, currently have laws mandating safety harness use on public hunting land, which comprises about 7 and $11 \%$ of each state, respectively. There is currently no research on the impact of these laws.

The National Electronic Injury Surveillance System (NEISS) shows that TSRI in the United States remain a persistent problem, with 3306 estimated TSRI in 2019. Most previous research has focused only on TSRI patients admitted to the hospital, with data sourced from trauma registries. ${ }^{5-10,14,15}$ These sources do not include nonadmitted or patients who present for outpatient services such as urgent care or primary care doctor visits. After an extensive literature review, we found only 4 studies that included nonadmitted and outpatient TSRI patients. ${ }^{4,11,16,17}$ This population is of interest not only in understanding the local incidence of TSRI, but also for the possibility that significant injuries occur that do not require admission.

This study characterizes injury patterns found in nonadmitted and admitted TSRI patients presenting to a level 2 Michigan trauma center. We also briefly review prevention efforts and novel interventions aimed at reducing TSRI.

\section{Methods}

Cases were obtained through a retrospective chart review of the Henry Ford Allegiance Health (HFAH) trauma registry and EPSi cost accounting database. Keywords searched included fall, hunter, tree, tree stand, treestand, ICD 9 diagnosis (E884.9_Other accidental fall from one level to another), and ICD 10 diagnosis (W14.XXXA_Fall from tree, initial encounter). The results captured both nonadmitted and admitted TSRI patients seen at HFAH or outpatient venues (eg, primary care clinic). Data sets were merged and duplicates removed. The time period of review ran from January 1, 2015 through December 31, 2019.

Inclusion criteria were age $>18 \mathrm{y}$ and fall from a tree stand. Variables tracked included age, sex, body mass index (BMI), injury severity score (ISS), abbreviated injury scales, disposition, alcohol use at time of incident, injuries sustained, reported height of fall, and narrative of the fall. The HFAH institutional review board approved the study. Data are reported as mean \pm SD. All analyses of the study data were performed using IBM SPSS Statistics Version 26. In comparing means across groups, the analysis of variation F-test was used with a cutoff $P$-value of 0.05 to determine statistical significance. 


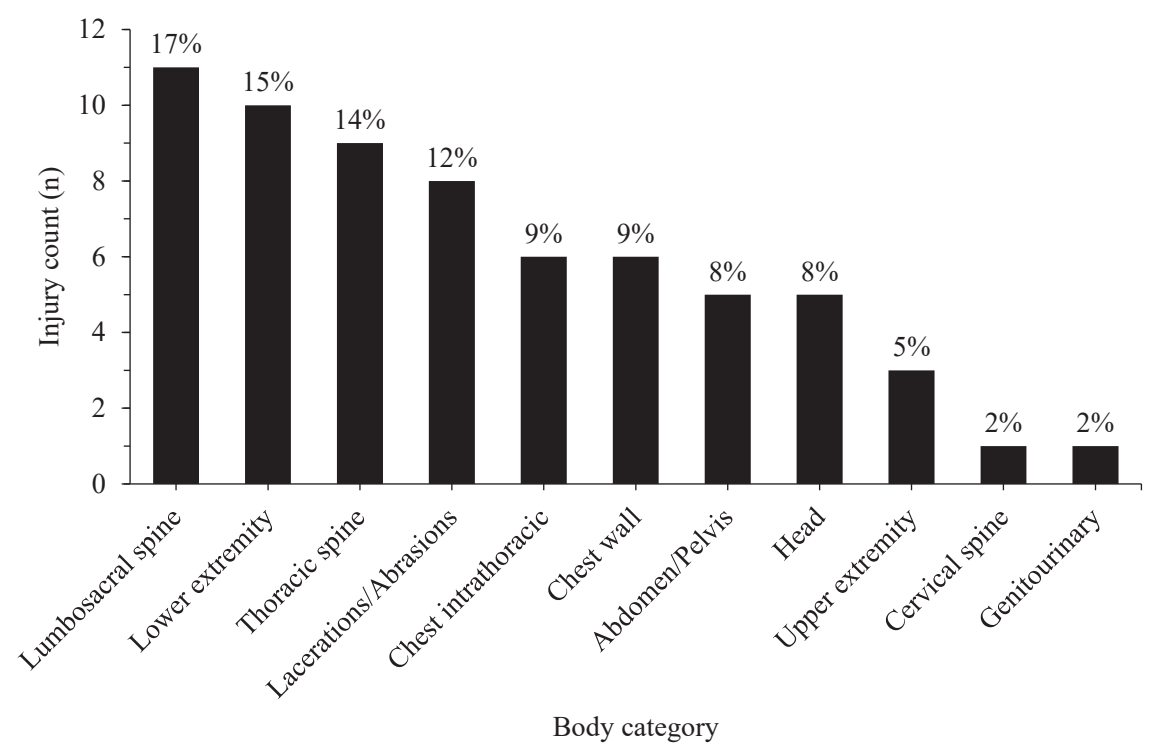

Figure 2. Injury count by body category in 33 patients with tree stand-related injury. Total number of injuries=65.

\section{Results}

Thirty-three patients were captured in our data review. All patients were male. Patient age was $45 \pm 13$ y. BMI for all patients was $30.8 \pm 6.6 \mathrm{~kg} \cdot \mathrm{m}^{-2}$. BMI in nonadmitted patients was $28.3 \pm 4.9 \mathrm{~kg} \cdot \mathrm{m}^{-2}$ versus $32.1 \pm 7.1$ $\mathrm{kg} \cdot \mathrm{m}^{-2}$ in admitted patients $(P=0.126)$. ISS for all patients was $9 \pm 10$, with a minimum of 0 and maximum of 45. ISS for nonadmitted patients was $2 \pm 1$ versus $13 \pm 11$ in admitted patients $(P=0.003)$. Reported height of fall for all patients was $5 \pm 2 \mathrm{~m}(17 \pm 5 \mathrm{ft})$, with a minimum of $3 \mathrm{~m}(10 \mathrm{ft})$ and a maximum of $9 \mathrm{~m}(30 \mathrm{ft})$. Reported height of fall for nonadmitted patients was $5 \pm 1 \mathrm{~m}(17 \pm 4 \mathrm{ft})$ versus $5 \pm 2 \mathrm{~m}(17 \pm 5 \mathrm{ft})$ in admitted patients. Fall arrest systems or harnesses were documented as being used in $4(12 \%)$ cases; in $5(15 \%)$ cases, harnesses were documented as not being used. There was no documentation about harness use or nonuse in the majority of patient charts $(\mathrm{n}=24 ; 73 \%)$. Alcohol use at the time of the incident was positive by laboratory ethanol test in 3 cases (9\%) and negative in 21 cases $(64 \%)$. Alcohol use was not documented or tested for in $9(27 \%)$ cases.

In the emergency department disposition category, 11 $(33 \%)$ patients were discharged home after evaluation and treatment (ie, nonadmitted). The remaining $22(67 \%)$ were admitted to the floor $(n=9)$, step-down $(n=1)$, operating room $(n=2)$, surgical intenstive care unit $(n=9)$ or transferred $(n=1)$. Ultimate disposition from the hospital was home for $27(82 \%)$ patients, and the remaining $6(18 \%)$ required some form of continued care (eg, rehabilitation or skilled nursing facility).

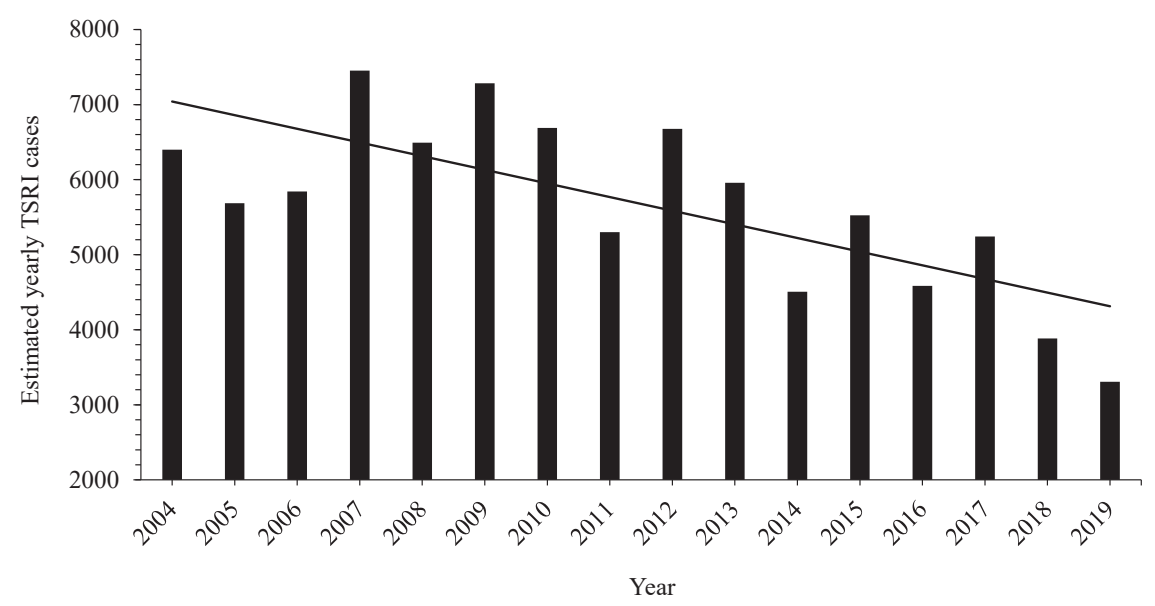

Figure 3. National Electronic Injury Surveillance System estimates of yearly tree stand-related injuries in the United States from 2004 through 2019. The trendline shows an overall decline in tree stand-related injury estimates. 
The most common injuries sustained were lumbosacral spine fractures in $11(17 \%)$, lower extremity fractures in $10(15 \%)$, and thoracic spine fractures in $9(14 \%)$. The least likely injuries were cervical spine fractures $(n=1$; $2 \%)$ and genitourinary $(n=1 ; 2 \%)$. All patients $(6$ of 6$)$ who sustained rib fractures had $>3$ ribs fractured. Of those who were injured, most patients were polytraumas with more than 1 body category involved $(n=18 ; 55 \%)$. Nonadmitted patients sustained various injuries, including contusions, abrasions, suspected nasal bone fracture $(n=1)$, medial malleolus fracture requiring outpatient surgery with podiatry $(\mathrm{n}=1)$, an L3 compression fracture requiring a back brace $(\mathrm{n}=1)$, a proximal fibular shaft fracture that resulted in chronic pain $(n=1)$, and complex scrotal/penis laceration with exposed testicle requiring urology evaluation and repair in the emergency department $(n=1)$. There was 1 fatality in the study. See Figure 2 for injury count and percentages by category.

\section{Discussion}

Consistent with prior studies, ${ }^{5-13}$ injury patterns in the data set predominantly involved spinal or lower extremity fractures. Harness use, documentation about harness use, and alcohol use at the time of the incident were low and similar to prior research on TSRI. ${ }^{8-10,12-15}$ There was a significant portion of cases in the nonadmitted category. Most nonadmitted patients sustained only minor injuries, but some had significant injuries requiring specialist consultation, orthopedic braces, and outpatient surgery. None of these nonadmitted patients were captured by the trauma registry.

Our study showed that BMI was higher in admitted patients compared to nonadmitted patients. Although this observation was not statistically significant, the difference across groups is sufficiently large that in a larger sample size this association might be statistically significant. A prior study showed that patients with a BMI $<25$ $\mathrm{kg} \cdot \mathrm{m}^{-2}$ and patients with a BMI $>25 \mathrm{~kg} \cdot \mathrm{m}^{-2}$ had similar ISS and Glasgow coma scale values, but those with a BMI $>25 \mathrm{~kg} \cdot \mathrm{m}^{-2}$ were more likely to go to rehabilitation facilities after their TSRI (36 vs 9\%, respectively). ${ }^{9}$ Our study did not show a statistically significant difference in ultimate disposition based on BMI $>25 \mathrm{~kg} \cdot \mathrm{m}^{-2}$ (nonadmitted $85 \%$ vs admitted $83 \% ; P=1.00$ ).

We found no statistically significant association between reported height of fall and ISS. Although there was no difference in the reported height of fall between the nonadmitted and admitted patients, there was a substantial difference in ISS. Only 2 studies were found that demonstrated an association between reported height of fall and severity of injury. One study found that tree stand falls $>3 \mathrm{~m}$ (11 ft) were associated with more severe neurologic injury (eg, radiculopathy, central cord syndrome, spinal cord injury). ${ }^{15}$ Another found that falls $>6$ $\mathrm{m}(20 \mathrm{ft})$ were associated with a higher ISS. ${ }^{9}$

Our data suggest that relying on a trauma registry alone may underestimate the local incidence of TSRI. One-third of the cases captured were not included in the HFAH trauma registry. Accounting for these "minor" falls is important because higher numbers can highlight the true extent of the problem and galvanize trauma prevention efforts. Another way to capture more TSRI cases is to mimic the compulsory reporting structure for huntingrelated firearm injuries, for which police file incident reports with local conservation officers. ${ }^{8}$ This is relevant because a hunter is statistically more likely to be injured by a falling from a tree ( 4.59 per 10,000 hunters $)^{6,17}$ than with a firearm (1.66 per 10,000 hunters). ${ }^{18}$

\section{TRACKING TSRI AND THE NEISS}

Unlike hunting-related firearm injuries, TSRI are not mandatorily reported to state game agencies in most states, including Michigan. One tool used to estimate TSRI nationally is the NEISS, a database organized by the Consumer Product Safety Commission that tracks US consumer product-related injuries. The database can be found at www.cpsc.gov/library/neiss.html. It comprises 100 variously sized (ie, patient volume/year) and located (ie, rural/urban) emergency departments across the United States that input data from emergency department visits nightly into the system. The database then uses statistical models to estimate the national number of incidents related to specific consumer products, including tree stands used for hunting. NEISS data are limited because the database is a sample of hospitals and therefore of cases; it is not a census, and the estimates have an associated variability subject to sampling error. The NEISS solely identifies patients who sought care in an emergency department, not including those seen in an urgent care center or physician office; thus, the true number of injuries is likely greater than captured in the database. Data may also be skewed toward more serious injuries that were deemed emergencies by presenting patients or providers. ${ }^{4}$

The NEISS estimates of yearly TSRI cases in the United States are declining (Figure 3); however, these data are tempered by the overall decrease in US big game hunters. The following incidence rates use NEISS data and refer to US big game hunters, unless otherwise specified. In 2006, there were 10.7 million hunters and an estimated 5.45 TSRI per 10,000 hunters. ${ }^{1}$ In 2016, there were 9.2 million hunters and an estimated 4.98 TSRI per 10,000 hunters. $^{3}$ 
Previous studies have used NEISS data to analyze both hunting-related firearm injuries ${ }^{18}$ and TSRI. ${ }^{4,17}$ One epidemiologic study of TSRI used NEISS data from 2000 to 2007 and showed an overall rate of 4.59 TSRI per 10,000 hunters per year. ${ }^{17}$ Another study used a novel regional electronic medical record that captured nearly all medical encounters related to TSRI for residents of north and central Wisconsin from 2009 to 2013. This study found an estimated rate of 6 TSRI per 10,000 local Wisconsin hunters in 2009 and 3.6 TSRI per 10,000 local Wisconsin hunters in 2013, which was not a significant change over 5 y $(P=0.79) .{ }^{16}$ Comparing these epidemiologic TSRI incident rates with much of the prior research is problematic because TSRI incident rates are not calculated or estimated in those studies. ${ }^{5-10,14,15}$ Most prior studies on TSRI use trauma databases that exclude nonadmitted patients, making incident rate estimates inherently inaccurate. ${ }^{5-10,14,15}$

According to our data, 33 TSRI cases from 2015 to 2019 amounts to an estimated 6.6 cases per year. HFAH serves as the only hospital in Jackson County, Michigan, and the only level 2 trauma center in a 37-mile catchment area. The estimated mean number of resident Jackson County deer hunters over that time frame was $11,519 .{ }^{19}$ Presuming most serious TSRI presented to our hospital, the yearly estimated TSRI case rate was 5.73 per 10,000 Jackson County deer hunters (95\% CI 3.94-8.05) from 2015 to 2019, which is consistent with NEISS estimates and previous epidemiologic studies. ${ }^{16,17}$

\section{PREVIOUS PREVENTION EFFORTS}

Incorporating tree stand safety material in hunter education classes has not universally demonstrated a decrease in TSRI. A 20-y study from the Pennsylvania trauma registry (1987-2006) showed that TSRI have actually increased significantly despite the inclusion of tree stand safety material in 1999 and reduced numbers of hunters. ${ }^{14}$ This may be due to a low rate of safety harness use among TSRI patients, which previous studies documented at 3 to $4 \% .^{10,15}$ Authors have noted that there is a high degree of underreporting and/or underrecording because harness use is often left out of the medical record. ${ }^{10,15}$ One study described a successful TSRI prevention strategy. In 1992, a tree stand safety educational campaign (ie, pamphlets and mailers) in Louisiana that focused on hunt clubs and sporting goods retailers resulted in a reduction in tree stand-related spinal cord injuries over the next 3 y. ${ }^{20}$ The results suggest an association, but the study is limited by a lack of randomization and an inability to exclude a myriad of variables. Some prior researchers have proposed state laws to mandate safety harness use. ${ }^{9}$ We speculate that such laws would be hard to enforce owing to difficulty in locating hunters, the large amount of man hours needed by state games agencies to find said hunters, and the unpopular aspect of disturbing game during their search. Lastly, a law can be enacted but not followed if a hunter does not buy-in to the importance of fall prevention.

\section{NOVEL PREVENTION EFFORTS}

Education is the cornerstone of any system to promote safer behavior. For some high-risk behaviors, education has proven to be not enough. To decrease severe injury from motor vehicle collisions, built-in safety mechanisms are now required or being implemented by manufacturers, such as seat belt warnings and automatic braking. Engineered safety mechanisms might be developed to improve tree stand safety. ${ }^{21}$ Engineered solutions to protect hunters are already in place, particularly in terms of firearm safety, such as blaze orange clothing, the gun trigger guard, and the trigger safety mechanism. ${ }^{22}$ There are no equivalent measures in TSRI prevention except for warning labels on the tree stand itself-a hunter must still choose to wear a harness. Some novel prevention efforts are reaching hunters though social media. In 2018, the Pennsylvania Game Commission began a highway billboard campaign to reduce TSRI. The billboards feature the silhouette of a tree stand and hunter with the text "wear your harness" and run annually from October 1 to midDecember. Michigan's DNR marketing strategies are shifting to include social media outreach through Facebook and other platforms that use geographic data from cell phones to target ad campaigns on hunter safety. They also use an email newsletter to propagate videos on firearm, boating, and tree stand safety each season. Currently, there is no research on the impact of these efforts.

\section{LIMITATIONS}

Study limitations include the retrospective design, small sample size, exclusion of patients $<18 \mathrm{y}$, incomplete medical documentation (eg, harness use), and reliance on patient reported details (eg, narrative of the fall). We also presumed that most, if not all, serious TSRI in our catchment area presented to our singular county level 2 trauma center to calculate the TSRI case rate for Jackson County. There were likely TSRI that occurred in Jackson County that either presented to another institution or did not present at all to a medical facility (ie, minor injuries), thus limiting our sample size. There is likely a reporting/identification bias because patients with more serious injuries would be more apt to seek medical care. 


\section{Conclusions}

We found that TSRI have considerable morbidity, mostly involving fractures of the spine and lower extremities. One-third of the patients in our study were nonadmitted, some of whom had significant injuries requiring specialist consultation, orthopedic braces, or outpatient surgery. The primary treatment for TSRI is prevention. Accurate reporting of both nonadmitted and admitted TSRI may allow for tracking the success or failure of prevention measures and can be used to educate the public and medical community alike. The authors recommend that, as a public health measure, and as with hunting-related firearm injuries, states should enact laws mandating reporting of TSRI and that state game agencies implement TSRI education efforts using social media and billboards during hunting seasons.

Acknowledgments: Madonna Walters, Denise Garrecht, Jessica Bammer, and Susan Huehl assisted with data collection and provided study guidance. David Metcalf and Candi Bachour provided statistical analysis.

Author Contributions: Study concept and design (AAL); acquisition of the data (AAL, BID, KWD, KRR); analysis of the data (AAL, BID, KWD, KRR); drafting of the manuscript (AAL, BID, KWD, KRR); critical revision of the manuscript (AAL, BID); and approval of final manuscript (AAL, BID, KWD, KRR).

Financial/Material Support: None.

Disclosures: None.

\section{References}

1. US Department of the Interior, Fish and Wildlife Service, and US Department of Commerce, US Census Bureau. National survey of fishing, hunting, and wildlife-associated recreation. Available at: https://www.census.gov/content/da m/Census/library/publications/2006/demo/fhw06-nat_rev_n ew.pdf. Accessed September 15, 2019.

2. US Department of the Interior, Fish and Wildlife Service, and US Department of Commerce, US Census Bureau. National survey of fishing, hunting, and wildlife-associated recreation. Available at: https://www.census.gov/content/ dam/Census/library/publications/2014/demo/fhw11-nat.pdf. Accessed September 15, 2019.

3. US Department of the Interior, Fish and Wildlife Service, and US Department of Commerce, US Census Bureau. National survey of fishing, hunting, and wildlife-associated recreation. Available at: https://www.census.gov/content/ dam/Census/library/publications/2018/demo/fhw16-nat.pdf. Accessed September 15, 2019.

4. Loder RT. Epidemiology of hunting stand injuries presenting to US emergency departments, 2008-2013. Wilderness Environ Med. 2015;26(3):387-94.

5. Pierre CA, Plog BA, Srinivasan V, Srinivasan K, Petraglia AL, Huang JH. Tree stand falls: a persistent cause of neurological injury in hunting. World $J$ Clin Cases. 2014;2(8):345-50.

6. Crockett A, Stawicki SP, Thomas YM, Jarvis AM, Wang CF, Beery PR, et al. Tree stands, not guns, are the midwestern hunter's most dangerous weapon. Am Surg. 2010;76(9):1006-10.

7. Halanski MA, Corden TE. Wisconsin firearm deer hunting season: injuries at a level I trauma center, 1999-2004. WMJ. 2008;107(1):20-4.

8. Gates RL, Helmkamp JC, Wilson SL, Denning DA, Beaver BL. Deer stand-related trauma in West Virginia: 1994 through 1999. J Trauma. 2002;53(4):705-8.

9. Carroll JT, Chapman AJ, Davis AT, Rodriguez CH. The impact of tree-stand falls on a level 1 trauma center in West Michigan. Am J Surg. 2016;211(3):555-8.

10. Metz M, Kross M, Abt P, Bankey P, Koniaris LG. Tree stand falls: a persistent cause of sports injury. South Med J. 2004;97(8):715-9.

11. Rose WD, Laird SL, Williams J, Veach JS, Laird JB. Treestand-related injuries: a wilderness emergency. J Wilderness Med. 1994;5:382-8.

12. Urquhart CK, Hawkins ML, Howdieshell TR, Masnberger Jr AR. Deer stands: a significant cause of injury and mortality. South Med J. 1991;84(6):686-8.

13. Fayssoux RS, Tally W, Sanfilippo JA, Stock G, Ratliff JK, Anderson $\mathrm{G}$, et al. Spinal injuries after falls from hunting trees stands. Spine J. 2008;8(3):522-8.

14. Smith JL, Lengerich EJ, Wood GC. Injuries due to falls from hunter's tree stands in Pennsylvania. Am J Prev Med. 2009;37(5):433-6.

15. Hamilton K, Rocque B, Brooks N. Spine and spinal cord injuries after falls from tree stands during the Wisconsin deer hunting season. WMJ. 2017;116(4):201-5.

16. VanWormer JJ, Holsman RH, Petchenik JB, Dhuey BJ, Keifer MC. Epidemiologic trends in medically-attended tree stand fall injuries among Wisconsin deer hunters. Injury. 2016;47(1):220-5.

17. Terry J, Griffin R, Rue 3rd LW, McGwin Jr G. Epidemiology of tree stand-related injuries in the United States from 2000 to 2007. J Trauma. 2010;68(3):712-5.

18. Loder RT, Farren N. Injuries from firearms in hunting activities. Injury. 2014;45(8):1207-14.

19. Frawley BJ. Michigan department of natural resources wildlife report No. 3691. August 2020. Available at: https:// www.michigan.gov/documents/dnr/2019_deer_harvest_sur vey_report_701035_7.pdf. Accessed October 10, 2020.

20. Lawrence DW, Gibbs LI, Kohn MA. Spinal cord injuries in Louisiana due to falls from deer stands, 1985-1994. J LA State Med Soc. 1996;148(2):77-9.

21. Voevodsky J. Evaluation of a deceleration warning light for reducing rear-end automobile collisions. J Appl Psychol. 1974;59(3):270-3.

22. Jones W, O'Hara M, Kautz J, Hutton B, Ackman D, Morse D. Hunting-associated injuries and wearing "hunter" orange clothing: New York, 1989-1995. MMWR Morb Mortal Wkly Rep. 1996;45(41):884-7. 